\title{
El hombre inútil en la literatura de Hispanoamérica: antecedentes del siglo xIX a la vanguardia
}

\section{The superfluos man in Latin American Literature: From the igth Century to the Avant-garde}

\author{
Karla L. Marrufo Huchim* \\ Centro Peninsular en Humanidades y Ciencias Sociales, \\ Universidad Nacional Autónoma de México ${ }^{* *}$, Mérida, México \\ ORCID: https://orcid.org/0000-0002-4161-0310 \\ ISSN-OI85-4259; e- ISSN: 2007-9I76 \\ DoI: http://dx.doi.org/I0.28928/ri/862019/atc3/marrufohuchimk
}

\begin{abstract}
Resumen
El objetivo del presente artículo es rastrear los antecedentes de la figura del hombre inútil en Hispanoamérica, sentando las bases de lo que llegaría a ser en la narrativa de vanguardia. La figura del hombre inútil es una de las más representativas de la contemporaneidad. Surge en Europa hacia finales del siglo xvirI, se consolida en el XIX, y encarna la crisis de la Modernidad, pues su inteligencia y plena conciencia del trayecto de las sociedades occidentales le lleva a percibir un panorama desalentador en el que no hay cabida para mirar hacia el futuro. En Hispanoamérica, la figura también surge y se consolida a lo largo del siglo xIx, adquiriendo matices particulares acordes con el contexto de las ciudades capitales de los países recién independizados y continuando su trayecto como protagonista de la narrativa vanguardista, donde se expresa un estadio más en la crisis del hombre moderno.

Palabras claveः narrativa hispanoamericana; estética literaria; Modernidad; figura literaria; risa.
\end{abstract}

\footnotetext{
Abstract

The objective of this article is to trace the background of the figure of the superfluous man in Latin America to identify the precedents of what this figure became in the Avant-garde narrative. The superfluous man is one of the most representative contemporary literary figures, it emerged in Europe in the $18^{\text {th }}$ century, consolidated in the $19^{\text {th }}$, and incarnates the crisis of Modernity. The figure stands up for his intelligence and full awareness of the conflicts of Western societies, which leads him to perceive a discouraging panorama and live with no hope about the future. In Latin America, this figure will also emerge and consolidate throughout the $19^{\text {th }}$ century, acquiring specific features in accordance with the context of the capital cities of the newly independent countries and continuing his development as a main character of the Avant-Garde narrative, which expresses a different moment in the crisis of the modern man. Key Words: Latin American narrative; Literary Esthetics; Modernity; Literary Figures; Laughter.
}

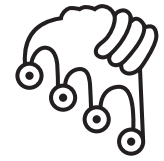

\section{IZTAPALAPA}

Agua sobre lajas

* karla.marrufo@gmail. com

** Programa de Becas Posdoctorales en la UNAM

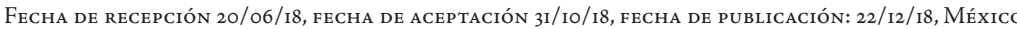




\section{Introducción}

L

a narrativa de vanguardia hispanoamericana ha sido caracterizada por tender a la fragmentación del discurso, por reducir el argumento a un mínimo de elementos a fin de privilegiar los juegos con el lenguaje y por articular textos lúdicos que dan cabida a la metanarración y la autoficción. ${ }^{1}$ En general, se ha estudiado como un tipo de escritura más atenta a las innovaciones tecnológicas de las primeras décadas del siglo xx, a la transformación de las urbes y, sobre todo, a sus nuevos modos de interacción; pero que también pone en evidencia las crisis individuales propias del mundo moderno.

Un repaso general por algunas de las principales obras narrativas vanguardistas nos puede dar una idea de lo anterior. Textos como La llama fría (1925) de Gilberto Owen, La casa de cartón (1928) de Martín Adán, Débora (1927) y Vida del ahorcado (1932) de Pablo Palacio, por mencionar algunos, son protagonizados por personajes (hombres) cuyas vidas parecen ir desdoblándose a lo largo del texto, pues en sus respectivas relaciones amorosas y sociales, y aun en el cotidiano andar, no parecen hallar certeza alguna, nada que pueda sostenerlos en medio de un contexto marcado por la inestabilidad. A través de ellos se pone de manifiesto una crítica que va desarticulando los rigores, no solo de la narrativa más tradicional, sino de la vida en varias de sus facetas. De esto dan razón las antes citadas novelas, así como el Libro sin tapas (1928) de Felisberto Hernández, El laberinto de si mismo (1933) de Enrique Labrador Ruiz y Papeles de recienvenido (1929) de Macedonio Fernández, entre otros.

La narrativa de vanguardia se construye muchas veces a través de narradores fragmentados, inconclusos, de dudosa identidad o en conflicto con ella, colocados

1 En «La heterogeneidad de la narrativa vanguardista hispanoamericana», Hugo J. Verani destaca las cualidades proteicas y diversas por donde discurre la narrativa vanguardista, enfatizando en su «carácter lírico, autoconsciente y fragmentario», la presencia de personajes que tienden a desvanecerse en la narración a la par con el hilo argumental, así como «una visión lúdica e irónica que intensifica la libertad expresiva y las aventuras de la imaginación» (I998: I17-II8). 
en escenarios regidos por la incertidumbre. Es posible entrever en estos conflictos una actitud lúdica e incluso la incorporación de situaciones absurdas o ridículas, pero en las que siempre subyace un cierto rastro del tan famoso malestar de fin de siglo sintomático de las letras finiseculares del XIx y que en la prosa vanguardista ha sido identificado por la crítica de varias maneras. Por ejemplo, en «La casa de cartón y el relato vanguardista hispanoamericano» Hugo J. Verani apunta:

En La casa de cartón Martín Adán se distingue por la radicalidad con que asume una nueva estética de la escritura: emprende una disolución de lo novelesco en la subjetividad lírica, en la discontinuidad, en el fragmentarismo y en la contextualidad disonante. Su mismo título, emblema de la estética vanguardista, alude a la fragilidad del mundo fenoménico y a la desconfianza ante una realidad objetiva. Si en la ficción realista la casa es un espacio protector, recinto mítico de la intimidad y de la identidad que sostiene la existencia de los personajes, aquí se convierte en un espacio deshabitado y de contornos evanescentes, producto de la imaginación. El autor construye explícitamente un simulacro, una arquitectura de papel, reducida a su condición de lenguaje, que no extrae sus andamios de la observación directa de la realidad, sino de lecturas literarias (1989: I078-I079).

Esta fragilidad identitaria, derivada de una experiencia del mundo como algo ajeno y poco confiable, también ha representado un punto crucial para la crítica en la obra de Palacio. En «Pablo Palacio: descrédito de la realidad, bolo suburbano y escritura», Alicia Ortega sintetiza así los conflictos del hombre moderno que atraviesan la obra del ecuatoriano:

Se trata entonces de una concepción moderna de la identidad ya que dicha categoría emerge ya no como una instancia construida y acabada monolíticamente, sino, más bien, como una entidad compleja y en un hacerse continuo; hecha ella misma de fragmentos, de historias inconclusas, de múltiples rostros que se adecuan al reclamo vital de discursos e ideas que no cesan de proliferar. La sensibilidad moderna habla también de sujetos que portan un saber insuficiente sobre ellos mismos; si la modernidad postula un mundo en el que todo lo sólido se desvanece en el aire, no hay mayor certeza que la imagen inconclusa de uno mismo: Palacio escribe sus cuentos desde esta conciencia irónica, moderna, autorreflexiva (20I4: I43).

En la narrativa de vanguardia es común encontrar personajes masculinos por el estilo: en plena crisis de identidad, negados para la acción, sin perspectivas hacia el 
futuro e incapaces de afrontar un estado de cosas, un sistema y una sociedad carentes de certezas, rasgos todos característicos de la figura del hombre inútil. De dónde viene esta figura, cómo se relaciona con el famoso malestar de fin de siglo, cómo y por qué llegó a convertirse en la protagonista de la narrativa vanguardista hispanoamericana, son algunas de las interrogantes que guiarán este artículo a fin de ofrecer un rastreo por los antecedentes de la figura del hombre inútil en Hispanoamérica y ver cómo se vinculan con la vanguardia desde esta perspectiva.

\section{La figura del hombre inútil: símbolo de la Modernidad}

En «El problema anímico del hombre moderno», ${ }^{2}$ Carl Gustav Jung discurre sobre el carácter inaprehensible de la Modernidad para situar la discusión en uno de los problemas que debe afrontar el hombre moderno: ubicado en una encrucijada histórica, se le exige con urgencia mirar hacia el pasado para tratar de encauzar el futuro, y hacerlo en un presente que está atestiguando el resquebrajamiento de lo que hasta entonces se había considerado la cumbre de la civilización. Para Jung, el hombre moderno se encuentra en un sitio privilegiado desde el cual puede adquirir una plenitud de consciencia respecto al presente: «por encima de él, el cielo; por debajo, la humanidad y su historia, que se pierde en la niebla primigenia; ante él, el abismo de todo futuro» (20II: 7I). Sin embargo, esta posición requiere una lucidez que solo unos cuantos logran alcanzar y que, además, los vuelve seres solitarios y profundamente críticos.

La Modernidad ${ }^{3}$ ha implicado para algunos una plenitud de consciencia, como apunta Jung, así como todo un reto que ha quedado de manera exclusiva en manos

2 Conferencia dictada en Praga en 1928, en el Congreso de la Asociación para la Cooperación Intelectual.

3 En adelante, entenderemos la noción de Modernidad siguiendo la propuesta de Luis Beltrán Almería en Simbolismo y Modernidad y en Genvs. Genealogía de la imaginación literaria. De la tradición a la Modernidad, quien no identifica un cambio radical, paradigmático, entre Modernidad y Posmodernidad, sino a esta última como una adecuación teórica de la primera: «La teorización posterior del modernismo ha sido un paso insuficiente, una solución ecléctica -realismo para el siglo xIx y modernismo para el siglo $\mathrm{xx}$ - que no da la medida del reto moderno. La interpretación posmoderna ha consistido en una adecuación de la teoría modernista al escepticismo rampante de las últimas décadas. Tanto las versiones realista, modernista o posmodernista comparten una mirada que se limita a la actualidad, olvidando la larga marcha del espíritu de la 
de la humanidad y al que habría que sumar la naturaleza contradictoria de los fenómenos de este periodo, el triunfo de la libertad y la suplantación de la idea de Dios y la de la Razón por la del individuo. Así lo explica Luis Beltrán Almería en Simbolismo y Modernidad: «La modernidad coloca en el centro del universo al individuo y en torno a él giran varias ideas esenciales. [...] Entre las grietas y espacios abiertos que ofrece la secuencia de ideas, el individuo puede elegir y escapar a la determinación de la idea única» (2015:143).

$\mathrm{Al}$ colocarse el individuo (moderno, libre) en el centro del orden universal, se inaugura una relación totalmente distinta con la Naturaleza y con la propia humanidad; una relación diversa, cambiante, contradictoria, que ha dado lugar a proyectos igualmente contradictorios que a la larga han fracasado o están a punto de hacerlo. ${ }^{4}$

Como cada faceta en la historia de la humanidad, la Modernidad ha ofrecido diversas respuestas estéticas a los retos que ha debido afrontar el hombre moderno; una de ellas es el simbolismo:

Los símbolos modernos son imágenes sincréticas, complejas. Bajo su apariencia unívoca contienen la lucha de contrarios y su sentido es ambivalente. El viaje, la prueba, la infancia, la educación, el drama familiar, la ciudad, lo demoníaco, el humor tragicómico, el hombre inútil, ciertas imágenes de la mujer -sobre todo, las activas-el andrógino... son algunos de los grandes símbolos modernos. En ellos el ser humano aparece como un ser dual: ángel y bestia, como había apuntado Blais Pascal. Esa dualidad se resuelve como una coalición contra un tercero que es el otro. Es decir, la misma Humanidad (Beltrán, 2017*363).

Entender la figura del hombre inútil como un símbolo de la Modernidad no solo implica dimensionarla en la encrucijada histórica de este periodo, sino apelar a sus posibilidades expresivas como figura emblemática. No se trata, pues, de un personaje en lo particular, ni de un arquetipo; el primero se define en el marco de obras (literarias, artísticas) específicas, y el segundo, desde la concepción de Jung, como una figura simbólica, sí, pero presente en ese repositorio común de la humanidad,

Humanidad. La teoría del simbolismo moderno trata de comprender el reto estético de la Modernidad como una etapa, la última por el momento de esta travesía del espíritu» (Beltrán, 2015: 119-120).

4 Beltrán Almería ejemplifica esto con dos proyectos en particular: el proyecto igualitario (comunismo) y el democrático (2015: II8). 
llamado inconsciente colectivo, desde el tiempo de las sociedades arcaicas (Jung, I970: IO-II).

El hombre inútil como figura representará la angustia, el desencanto, la negación para actuar en un mundo que comienza a mostrar el fracaso de sus proyectos civilizatorios y en el que el individuo debe hacerse cargo, él solo, del futuro de la humanidad. Para llegar a esta crisis, el hombre moderno debe ser plenamente consciente de su devenir histórico, según anotaba Jung, pero el mismo autor advierte sobre el riesgo de llevar esta plenitud de consciencia al extremo de la inutilidad,

pues nada hay más fácil que afectar esta consciencia, y de hecho hay toda una horda de inútiles que se dan aires de modernidad, saltándose fraudulentamente todos los escalones que representan otras tantas tareas vitales sumamente dificultosas, y que surgen de repente, como espectros desarraigados, vampíricos, junto al verdadero moderno, desacreditándole en su poco envidiable soledad (Jung, 20II: 72).

Estos rasgos, sintomáticos de la figura del hombre inútil, no son nada nuevo en las primeras décadas del siglo $\mathrm{xx}$, sino que venían perfilándose desde varios decenios atrás en distintas latitudes.

En la literatura rusa del siglo xix e inicios del xx, por ejemplo, la figura protagonizará obras emblemáticas de este periodo, como Noches blancas (1848) de Fiodor Dostoievski, Diario de un hombre superfluo (I850) de Iván Turguénev, Oblomov (1859) de Iván Goncharov y La vida de un hombre inútil (1907) de Máximo Gorki, entre otras. Incluso Oblomov, el protagonista de la novela homónima de Goncharov, llegaría a erigirse como representante de un mal cada vez más común en la época: el oblomovismo. En 1859, el crítico Nikolai Dobrolyubov publica un artículo titulado «QQué es el Oblomovismo?», donde explica que este consiste en una profunda inercia derivada de la apatía manifiesta hacia cualquier acontecimiento del mundo. ${ }^{5}$ Para el crítico, este mal suele presentarse en caballeros jóvenes, con recursos económicos (al menos en apariencia), ${ }^{6}$ elegantes, que se desenvuelven en un círculo social elitista y quienes nunca han tenido que preocuparse por resolver ningún asunto de la vida práctica, puesto que siempre han contado con uno o varios sirvientes encargados de

5 La traducción es propia. La versión en inglés dice: «Utter inertness resulting from apathy towards everything that goes on in the world» $(2018: 344)$.

6 Recordemos que en el caso particular de Oblomov, este se encuentra hundido en deudas, sin embargo, sigue llevando, mal que bien, el estilo de vida de sus antepasados y se niega rotundamente a mudar de rutina y vivienda. 
asistirles aun en las más nimias actividades (vestirse, peinarse, lavarse). En el caso del personaje protagónico de Goncharov, a pesar de haber recibido una educación elitista, no ha sido capaz de hallar en ese conocimiento algo que le procure utilidad alguna; por eso las lecturas que le facilitan sus amigos no le generan el menor interés $y$, en general, nada de lo que tiene por ofrecer su entorno es capaz de sacarle de su estado de inercia.

En Europa también habríamos de encontrar obras literarias y reflexiones en torno al arte que se aproximan a la crisis del hombre moderno, a las posibles reacciones o actitudes ante ella y entre las que figuran variantes del hombre inútil. En I860, Charles Baudelaire publica El pintor de la vida moderna, un lúcido ensayo sobre las costumbres burguesas de la época, el arte y la moda, perfilados desde una Modernidad entendida por el autor como «lo transitorio, lo fugaz, lo contingente, la mitad del arte, cuya otra mitad es lo eterno e inmutable» (2014: 22). Para Baudelaire, los aspectos de la vida moderna se ven necesariamente atravesados por una fugacidad producto del cambio histórico, por eso su ideal de belleza guarda siempre algo permanente a lo largo de los siglos; pero también involucra un elemento propio de las circunstancias particulares de cada época y espacio, de ahí su interés por retratar la moda, los afeites, las formas de entretenimiento y las novedades en general, porque en todo ello se encuentra esa mitad transitoria, fugaz, contingente, inherente a la presencia de lo humano en un momento dado de la historia. En este sentido, Baudelaire identificaría al dandi como uno de los personajes representativos de la época; lo consideraba un hombre de espíritu superior, capaz de aprehender la belleza en medio de la fugacidad del momento actual y de cultivarla todos los días en su persona. Esta actitud no estará exenta de una inutilidad voluntaria, asumida a consciencia, pues como afirma el propio Baudelaire, «La belleza característica del dandi consiste sobre todo en la frialdad que se dimana de la inquebrantable resolución de no conmoverse; es como si fuera un fuego latente que se deja adivinar, que podría pero no quiere brillar» (20I4:44). Si bien el autor lo ubica en el contexto francés de la segunda mitad del xix, lo cierto es que el dandi habría de figurar en el arte de varias latitudes incluso hasta las primeras décadas del siglo xx.

En Estados Unidos, dos de las expresiones más relevantes del hombre inútil las encontramos en «Wakefield» de Nathaniel Hawthorne y en Bartleby, el escribiente (I853) de Herman Melville. El primero, publicado en I837 en el volumen titulado Twice Told Tales, consiste en la recreación de lo que tal vez pasó por la mente de Wakefield, un hombre que, excusando un viaje de unos cuantos días, abandona a su mujer durante veinte años para encerrarse en un pequeño apartamento situado a una cuadra de la que era su casa. Nunca conocemos de primera mano al protago- 
nista, pero lo que nos ofrece el narrador es una caracterización de la mediocridad, la pasividad y el extraño egoísmo del protagonista, rasgos que llegarían a ser distintivos de la figura del hombre inútil. Wakefield es descrito como un esposo constante pero esta constancia es producto de su lentitud, falta de vigor y tendencia a la comodidad; se le reconoce cierta inteligencia pero una más bien pasiva, sin propósito; es descrito como un ser sin imaginación ni originalidad y con un corazón no dispuesto a emociones fuertes. En síntesis, el narrador lo exhibe como un hombre intrascendente, sin presencia en el hoy y sin motivos para ser recordado el día de mañana.

En el texto de Melville, también conocemos al protagonista a través de los ojos de alguien más, en este caso del abogado para quien Bartleby entra a trabajar como copista. Desde la primera impresión que causa en el narrador, se advierte en el personaje un desencanto que sólo irá acentuándose conforme avance el relato: «En contestación a mi aviso, un joven inmóvil apareció una mañana en mi oficina; la puerta estaba abierta pues era verano. Reveo esa figura ¡ ¡ pálidamente pulcra, lamentablemente decente, incurablemente desolada! Era Bartleby» (Melville, 1999: 28).

La inutilidad de este personaje gira en torno a todo aquello vinculado con la vida práctica. Es un hombre que vive única y exclusivamente para desempeñar la labor que le han encomendado en principio en la oficina de abogados, y para nada más. Cada petición o solicitud de su jefe es replicada con un «preferiría no hacerlo», negación que será llevada al extremo cuando Bartleby sea desplazado y termine sus días prefiriendo no comer y no vivir más.

En ambos casos la actitud de los personajes hacia la vida presenta un conflicto que va mucho más allá de la aparente simplicidad del argumento. En Wakefield, el narrador reflexiona sobre el carácter tan absorbente del sistema en que se desenvuelven los individuos, al grado de que cualquier intento por apartarse de él, como el llevado a cabo por el protagonista, puede terminar por desterrarlo de su sociedad y aun del universo. ${ }^{7}$ En Bartleby, el epílogo nos dice que su incurable desolación y su negativa para actuar probablemente derivaban de su antiguo trabajo en el archivo muerto de una oficina postal, es decir, del conocimiento de primera mano de la inutilidad y la improcedencia de los esfuerzos humanos vertidos en cartas, promesas, absoluciones y mensajes urgentes que nunca llegaron a su destino.

7 Dice al final: «Amid the seeming confusion of our mysterious world individuals are so nicely adjusted to a system, and systems to one another, and to a whole, that by stepping aside for a moment a man exposes himself to a fearful risk of losing his place for ever. Like Wakefield, he may become, as it were, the outcast of the universe» (Hawthorne, 1920: 99). 
En estos ejemplos, la figura del hombre inútil, en tanto que figura estética, cumple la función de "dotar de imágenes, cada vez más complejas, útiles para afrontar los retos de la gran travesía de la humanidad. [... Nietzsche comprendió que el paso que había dado el hombre moderno era un gran salto. Se había despojado de la protección de los dioses y ponía en sus manos el destino del mundo" (Beltrán, 20ı6: 10).

Vista así, la figura del hombre inútil representa simbólicamente la crisis ante tamaña responsabilidad, pero sobre todo la expresión de la libertad y la toma de una decisión: la de no ser responsable de ese gran reto, la de permanecer impasible mientras todo se desmorona alrededor, la de hacer una gran pausa en el curso de la vida, como Wakefield, la de elegir no actuar, como Bartleby, la de no levantarse de la cama ni para bien ni para mal, como Oblomov; en fin, la de asumir a plenitud una libertad de actuar encaminada a la inacción.

En la Hispanoamérica del siglo xıx, la figura del hombre inútil no fue menos prolífica que en otros países, pues estuvo vinculada a ciertas manifestaciones de la literatura costumbrista, así como al llamado mal de fin de siglo y a las estéticas decadentista y modernista. La presencia de la figura en estas vertientes es la que habría de fungir como antecedente del hombre inútil de la narrativa de vanguardia, ya que, como veremos a continuación, muchos de los rasgos de la figura en el xix habrían de decantarse hacia esos personajes desencantados, enfrentando crisis identitarias, atrapados en un mundo contradictorio, fragmentario y lleno de incertidumbres sintomático de las vanguardias.

\section{Del pollo al dandi: el hombre inútil en el siglo xIx hispanoa- mericano}

Entre las transformaciones más notorias que sufrieron las principales capitales hispanoamericanas en las primeras décadas del siglo xıx se encuentra la proliferación de cafés. Santiago de Chile, Buenos Aires y la Ciudad de México ${ }^{8}$ fueron incorporando este tipo de establecimientos a la vida cotidiana como sitios de esparcimiento, socialización, convivio e intercambio de ideas. En «El café: refugio de literatos, polí-

8 Véase, por ejemplo, «Ámbitos de sociabilidad en Buenos Aires: despachos de bebidas y cafés, I860-I900» de Sandra V. Gayol; Los cafés literarios en Chile de Manuel Peña Muñoz; «El café: refugio de literatos, políticos y de muchos otros ocios» de Clementina Díaz y de Ovando. 
ticos y de muchos otros ocios», Clementina Díaz y de Ovando ofrece una singular descripción de este tipo de espacios en la Ciudad de México:

En muy poco tiempo, los cafés se convirtieron en el palpitante corazón de la ciudad, eran sitios en donde se ventilaba el discurrir de la vida cotidiana. Los cafés fueron lugares de placentera charla y fructífera tertulia literaria, ideales para la convivencia social, mentideros en donde la murmuración era deleitoso y diario ejercicio; a menudo hicieron las veces de gabinetes de lectura; allí los parroquianos podían leer los periódicos y, por lo mismo, cumplir a maravilla con esa trascendente función pública; fueron a la vez importantes centros de conspiración y espionaje, verdaderos clubes políticos, en ellos se debatían todos los inquietantes acontecimientos políticos de actualidad (2005: 75).

Además, los cafés se volvieron espacios idóneos para el ocio, pues la concurrencia también estaba conformada por diversidad de personajes, como desempleados, vagos, jóvenes sin dinero ni provecho, clérigos, comediantes, actrices, etc. A propósito de lo anterior y remitiendo a Luis González Obregón en La vida en México en 1810, Díaz y de Ovando apunta que era frecuente encontrar en esos lugares a ciertos personajes «estrafalarios» a los que llamaban «petimetres», o mejor conocidos como «recetantes, planchados, currutacos o manojitos mexicanos, abuelos de los lagartijos de fin de siglo [...] sin oficio ni beneficio, [que] iban a los cafés en busca de una invitación para llenar su vacío estómago. Intervenían sin que nadie los llamara, con ínfulas de eruditos, en todas las conversaciones y en una jerga en la que mezclaban palabras extranjeras» $(2005: 76)$.

A estos personajes también llamados «pollos», habría que agregar a los dandis: caballeros ricos, elegantes, a veces acompañados de mujeres pertenecientes a las élites, o dedicados al intercambio de ideas e impresiones sobre el diario acontecer, el arte, los espectáculos y la literatura. ${ }^{9}$

Estos lugares de entretenimiento, con sus respectivos personajes, son los que empezarían a llenar las páginas de los diarios y las gacetas de publicación periódica. En crónicas, cuentos, novelas y grabados caricaturescos del siglo xix es común

9 A este respecto Díaz y de Ovando ofrece una clara imagen del dandi encarnada en Manuel Gutiérrez Nájera, asistente asiduo al Gran Café de la Concordia en la Ciudad de México: «allí se podía encontrar al Duque Job, con su flux claro, levita cruzada, gardenia en el ojal, fumando su puro, bebiendo a sorbitos su coñac o departiendo en "dulce charla de sobremesa" con el enorme caricaturista José María Villasana, con Manuel Puga y Acal y con otros literatos» (2005:82). 
encontrar «pollos» y dandis, las más de las veces satirizados y llevados al extremo del ridículo. Los primeros solían ser blanco de textos costumbristas en los que los autores se regodeaban en la exhibición burlesca de sus mañas y vicios. Ejemplos representativos los encontramos en el cubano Luis Victoriano Betancourt, quien en su artículo titulado «Los pollos» (I867) presenta una minuciosa caracterización de estos personajes, destacando su inmadurez, vanidad, afeminamiento, frivolidad, ignorancia, propensión a la vida ociosa, a los bailes y a los amores pasajeros. Algunas semejanzas guardan estos «pollos» cubanos (aunque el autor señala que los hay en todo el mundo) con ciertos personajes tipo incluidos en Los cubanos pintados por sí mismos (I852), como el estudiante, el vividor y el amante de ventana; este último caracterizado por pasar largas horas frente al tocador, por su elegancia, su vestir a la moda y su constante ir en busca de aventuras amorosas. Incluso en las Cartas de don Caralampio Molinero del Cerro... (1860) de Ignacio Belauzarán, hay una carta dedicada a la descripción de estos personajes, una vez más distinguidos por su excesivo afeminamiento, elegancia, preocupación por la moda y los afeites; por evidenciar una ignorancia supina que se traduce en una palabrería rebuscada y vacía, por tener fortuna o aparentar tenerla y, en general, por llevar una vida inútil, improductiva, negada para el trabajo y dedicada al cultivo de la apariencia personal y los amores de ocasión.

En I890, José Tomás de Cuéllar ofrecerá una ingeniosa «Monografía del pollo» en el capítulo V de su novela Ensalada de pollos (2005ः 3I-39), donde distingue cuatro tipos: «pollo fino», «hijo de gallina "mocha" y rica, y gallo de pelea, ocioso, inútil y corrompido por razón de su riqueza»; «pollo callejero», «bípedo bastardo o bien sin madre, hijo de reformistas, tribunos, héroes, matones y descreídos, que de puro liberales no les ha quedado cara en qué persignarse»; «pollo ronco», «de la raza del callejero, que llega al auge de su preponderancia, que es el plagio»; y «pollo tempranero», «que se distingue en su primer emplume por sus avances; de manera que es más tempranero el que con menos edad tiene más vicios y el corazón más gastado» $(2005 \div 32) .{ }^{10}$

Más allá de las particularidades que cada autor reconoce en los personajes denominados «pollos», en lo general es posible advertir el predominio de una tendencia a

10 Además de estas variantes del «pollo», De Cuéllar inicia la novela con un hombre inútil pero pobre: don Jacobo Baca, hombre maduro que ha pasado por un sinfín de oficios sin destacar en ninguno, cuyas dotes para la lectura y la escritura son bastante dudosas, y cuya inutilidad le ha llevado a idear, en medio de la ociosidad y los vicios, el enrolarse en la revolución, donde por cierto también habrá de fracasar. 
la inutilidad, por lo menos en lo que se refiere al trabajo, así como una cierta devoción por el cuidado personal, el aspecto físico, la moda y los devaneos amorosos. Aunque solo he citado unos cuantos ejemplos, estos personajes fueron bastante comunes en la producción literaria decimonónica, en especial la identificada con la línea costumbrista y satírica. Algunos de los rasgos ya señalados habrían de ser caros a la figura del hombre inútil en el siglo xIX, aunque en otros casos se apartaría de esta imagen del «pollo» al presentarse como un personaje inteligente y lúcido, pero negado para la acción. ${ }^{11}$ Si seguimos la taxonomía de José Tomás de Cuéllar, podríamos vincular al «pollo fino» con el dandi en tanto que ambos comparten un cierto refinamiento producto de una posición social bastante acomodada (que en el pollo puede ser solo pretensión, pero en el dandi es necesaria) y una tendencia al ocio.

Quizá uno de los ejemplos más emblemáticos de lo anterior sea el protagonista de Don Catrín de la Fachenda (1818) de José Joaquín Fernández de Lizardi, pues ciertos rasgos en su caracterización llegarían a ser representativos del dandi finisecular. Don Catrín ha nacido en un hogar pobre, limpios sus padres de "toda mala raza, y también de toda riqueza" (2015:4), sin embargo predominan en él una vocación por la vida fácil, por los lujos, por la vida bohemia de los cafés de la época y por una total negación para cualquier asunto que tenga que ver con la vida práctica y productiva. $\mathrm{Al}$ igual que Oblomov, don Catrín desdeña el conocimiento y la educación, pues no parecen aportarle nada que contribuya a la vida regida por la ley del mínimo esfuerzo a la que aspira:

¿Qué se me da, amados catrines, parientes, amigos y compañeros, qué se me da, repito, de leer así o asado, de sumar veinte y once son treinta y seis, y de escribir, «el cura de Tacubaya salió a casar conejos»? [...] ¿Qué se me da, vuelvo a deciros, de estas y semejantes importunas reconvenciones? Nada a la verdad, nada seguramente; porque yo he tratado y visto murmurar a muchos ricos que escribían de los perros; pero a vuelta de estas murmuraciones los veía adular y recomendar por los más hábiles pendolistas del universo; lo que hace creer, queridos míos, que todo el

${ }^{11}$ En este punto es importante destacar que el personaje del pollo, aunque guarda como punto de contacto con la figura del hombre inútil algunos de los rasgos antes referidos (negación o incapacidad para la acción, en ciertos casos inteligencia y lucidez, una tendencia a la frivolidad), no siempre se trata de un hombre inútil, pues las más de las veces los pollos se quedan en la superficie de la crítica satírica, carecen de una mirada profunda, compleja y problemática de su entorno y devenir; mientras que como ejemplificaré más adelante, el hombre inútil suele representar simbólicamente y de manera compleja una crisis de su tiempo. 
mérito y habilidad del hombre consiste en saber adquirir y conservar el fruto de los cerros de América (2015:6).

En el caso de don Catrín, no se trata pues de una inutilidad derivada de la lucidez y el desencanto, sino más bien del cinismo de quien comulga con la idea de que lo ideal es ser rico sin importar si se es ignorante, falso y pretencioso. Sus vínculos con el dandi tienen que ver con una tendencia a la frivolidad, tanto en el vestir y en el aspecto físico en lo general, como en los temas de conversación y las relaciones sociales; no es casual que el mejor amigo de don Catrín se llame Precioso y sea descrito como un "joven no sólo fino sino afiligranado, de una erudición asombrosa, de unas costumbres ejemplares" (2015ः 15). Esta descripción es, desde luego, irónica, pero ejemplifica muy bien la tendencia a exagerar los rasgos de personajes por el estilo. En el caso de don Catrín, también encontramos ciertos rasgos del trickster en tanto que actúa muchas veces como un burlador o farsante en busca de oportunidades para llevar una vida holgada, y en esto se distancia del hombre inútil.

En el caso particular del dandi, el hastío, el aburrimiento, la desidia, la abulia y una permanente inapetencia e inconformidad, son algunos de los estados emocionales que determinarán su vida. Para esto es necesaria la holgura económica, que no solo se traduce en el lujo y la posesión de bienes, sino en una actitud hacia la vidaः «la palabra dandi denota refinamiento de carácter y una comprensión sutil del mecanismo moral del mundo; pero, por otro lado, el dandi aspira a la insensibilidad [... E El dandi está hastiado, o finge estarlo, por política y cuestiones de casta» (Baudelaire, 2014:17). El dandismo representa un modo de ser y de estar, atravesado por una noción muy particular de espiritualidad derivada del ocio consagrado a la consecución del placer y donde la elegancia material, producto de un refinamiento y sofisticación en el vestir y el empleo de afeites, no es frivolidad sino «símbolo de la superioridad aristocrática de su espíritu» (Baudelaire, 20I4:4I). ${ }^{12}$ Si bien es posible rastrear históricamente las manifestaciones del dandismo, Baudelaire reconoce que «aparece sobre todo en periodos de transición, cuando la democracia no es aún todopoderosa, cuando la aristocracia se tambalea y envilece solo parcialmente» (20I4: 43). Esto explica su auge en las últimas décadas del siglo XIX, cuando triunfan

12 Antes, el autor ha afirmado: «El hombre rico y ocioso y que, incluso hastiado, no tiene otra ocupación que ir en pos de la felicidad; el hombre educado en el lujo y acostumbrado desde su juventud a que otros le obedezcan, quien, al fin y al cabo, no tiene otra profesión que la elegancia, gozará siempre, en todas las épocas, de una fisonomía distintiva, apartada de la de los demás» (Baudelaire, 20r4: 40). 
el individualismo y la libertad, mecanismos ambos para hacer de los ciudadanos tablas rasas a la deriva en busca de una identidad, por lo menos, un poco estable.

El dandi habría de estar vinculado al famoso spleen también llamado malestar o tristeza de fin de siglo, que presenta puntos de contacto con el oblomovismo, y que en Hispanoamérica estaría relacionado con las estéticas modernista y decadentista. En una de sus publicaciones de la Crónica semanal de I89o, Julián del Casal explica en qué consiste la tristeza de fin de siglo:

En ningún final de siglo más que en el nuestro se han visto cosas tan contradictorias e inesperadas. De ahí ha nacido en los espíritus una incertidumbre que cada día reviste caracteres más alarmantes. El análisis nos ha hecho comprender que, después de tantos siglos, no es posible determinar a punto fijo el progreso de la humanidad. Más bien se puede afirmar que ha retrocedido, porque ha amado muchas cosas que hoy sólo puede odiar. Tanto desespera ese estado de ánimo que muchos de los seres que lo experimentan se despeñan por los riscos de la extravagancia, no por afán de llamar la atención, sino por olvidarse de que no pueden creer en nada, $y$ porque sienten al mismo tiempo la necesidad imperiosa de albergar en su alma alguna creencia.

Sabiendo que ese estado no se puede prolongar, porque nos hace la vida insoportable, se cree vagamente que el remedio será descubierto en la década que resta de siglo; pero como se teme también que las muchedumbres hambrientas promuevan un gran cataclismo social, la incertidumbre de que he hablado, o sea, la tristeza de fin de siglo, se va introduciendo, como los microbios de una epidemia, en todos los espíritus, no sólo de Europa, sino de todos los países civilizados (Del Casal, i899-189o, s/p).

Hacia finales del xix, hablar de esta especie de pandemia inherente al hombre moderno se había vuelto moneda corriente. En Perversos y pesimistas. Los escritores decadentistas en el nacimiento de la modernidad, José Mariano Leyva identifica el «nacimiento del hastío» característico de los decadentistas en México con un resquebrajamiento de las sociedades modernas, derivado de conflictos bélicos (en particular de la guerra francoprusiana) que representaron el fin del sistema político francés, tenido como modelo civilizatorio para los países occidentales, y expresado en una proliferación de tendencias artísticas, literarias, aglutinadas bajo el nombre de moderne o moderniste y que llevaban la impronta del fin de siècle. Sin embargo, y sin negar la influencia de la literatura francesa, se trata de un fenómeno mucho más generalizado, que en Hispanoamérica se encuentra también asociado a los procesos 
de consolidación de las élites de las grandes urbes de los países independientes, como Buenos Aires o la Ciudad de México.

Más que detenerme en las discusiones en torno a qué son el decadentismo o el modernismo, me interesa recuperar algunas de las nociones atribuidas a estas estéticas para vincularlas con la figura del hombre inútil en Hispanoamérica. ${ }^{13}$ Uno de los ensayos más elocuentes a propósito del decadentismo es "Valor estético de las obras de la escuela decadentista» de Atenedoro Monroy, texto ganador de los juegos florales convocados por el Colegio del Estado, en la ciudad de Puebla, en 1902. Desde las primeras páginas, el autor alude a la volatilidad del término decadentista, que da razón de la volatilidad del movimiento como propuesta estética. ${ }^{14}$

La postura crítica de Monroy resulta crucial para entender el trasfondo moral, ideológico y filosófico ${ }^{15}$ que subyace a la propuesta estética finisecular identificada con estas líneas de producción, pero sobre todo para articular una lectura más cabal de la figura del hombre inútil en las obras que participan de ella. Lo que Julián del Casal entiende como una enfermedad finisecular signada por la contradicción, para Monroy será paradoja expresada en arte, pues quienes han reflexionado sobre el decadentismo coinciden

en señalarle como caracteres de fondo cierta amargura intensa, cierto desencanto $y$ hastío de la vida, [...] un sinsabor y un desencanto que rayan en nirvana paradójico

${ }^{13}$ Considero pertinente esta precisión, pues en adelante me estaré basando en Atenedoro Monroy, quien no distingue o dice no distinguir entre modernistas, decadentistas, simbolistas y delicuescentes; e incluso emplea estos términos como sinónimos a lo largo de su ensayo. Darío, Lugones, Leopoldo Díaz, Balbino Dávalos, Amado Nervo, José Juan Tablada y Salvador Díaz Mirón son algunos de los autores que Monroy identifica como decadentistas. Si bien, no considero que estos términos sean sinónimos, tampoco encuentro necesario ahondar en cada uno de ellos y en sus implicaciones en este estudio, sino concentrarme en los rasgos destacados desde la postura de un crítico de la época y cómo se relacionan con la figura del hombre inútil hispanoamericano finisecular.

${ }^{14}$ Dice Monroy: «Pudiera pensarse que el nombre no hace á la cosa, y más que no todos los corifeos del decadentismo están conformes con esta denominación, pues algunos, siguiendo á Floupette, prefieren la de delicuescencia; otros, la de simbolismo; no pocos, la de modernismo, etc., etc.; mas tan significativo mote ya es por sí solo indicación bastante de lo que substancialmente envuelve la novísima manera ó procedimiento poético de que trato» (1902: 5).

${ }^{15}$ Para ahondar en estos aspectos véase «Atenedoro Monroy. Preceptiva y política en el fin del siglo xix» de Leondardo Martínez Carrizales, incluido en De la perfecta expresión. Preceptistas iberoamericanos siglo XIX. 
en que se quiere morir y vivir al mismo tiempo, y que, anunciando, por un lado el agotamiento de la voluntad, el cansancio y la pesadilla, y, por otro, el más sutil de los refinamientos de la sensibilidad, la hiperestesia y la neurosis, hacen de la literatura decadente un caso auténtico e irrefragable de Sicopatía [sic] (1902: 25-26).

Vale la pena detenerse en este último aspecto a propósito de «los refinamientos de la sensibilidad», pues es identificable en obras literarias donde los personajes masculinos, debido a su exacerbada sensibilidad y lucidez, a veces aunadas a una vida de hastío producto de haber llevado la experiencia al límite, terminan incurriendo en lo que para la época se consideraban patologías (zoofilia, homosexualidad, fetichismo), en violaciones, suicidios o en prácticas esotéricas. Además de lo anterior, en varios de estos textos se retoman elementos sobrenaturales, como los pactos con el diablo y la intervención de seres fantásticos, como demonios, hadas, etc. Ejemplo hispanoamericanos de lo anterior son: «La Diablesa» de Amado Nervo, donde Jaime, harto de haber viajado, amado y vivido todas las experiencias imaginables a sus 33 años, invoca al Diablo (quien, por cierto, está caracterizado como dandi) para pedirle a la mujer ideal, síntesis del eterno femenino; o «El pájaro azul» de Rubén Darío, donde se narra la vida bohemia de Garcín, un poeta que cree tener un pájaro azul dentro de la cabeza y termina dándose un balazo para liberarlo. ${ }^{16} \mathrm{En}$ estos textos, los protagonistas son jóvenes, con una sensibilidad particular que les implica una negación para la vida útil, desde donde la realidad es percibida como algo insuficiente e insatisfactorio, y cuyas búsquedas exhibirán los matices de otra figura estética, la del loco. ${ }^{17}$

Aunque Monroy se enfoca en el decadentismo francés, también perfila su crítica hacia el hispanoamericano, teniendo como uno de los mayores despropósitos el pensar que el espíritu americano, su juventud histórica y su promisorio futuro son compatibles con la decadencia de la vieja Europa. Por eso las manifestaciones simbolistas, decadentistas e incluso modernistas surgidas en América le resultan una

16 Otros autores que desarrollaron argumentos similares son: José Asunción Silva en De sobremesa (I895-I896), Carlos Díaz Dufoo en Cuentos nerviosos (1900), Efrén Rebolledo en El enemigo (1908) y Amado Nervo en El bachiller (1895).

17 Monroy ofrece esta definición del decadentismo: «escuela poético-lírica de origen metafísico, en que se traduce un hondo y amargo malestar social de cansancio y decrepitud, por medio de símbolos obscuros é ininteligibles, expresiones rebuscadas ó alteradas caprichosamente en su significación, metros de calculadas disonancias ó virtualidades musicales de absoluta libertad y novedad, rimas regresivas, y fantaseos y alucinaciones personalísimos, propios sólo de la neurosis y el desequilibrio cerebral» (1902: 30). 
impostación, una imitación vacua de los males del Viejo Mundo, donde sí resultan un poco más comprensibles la desazón y el desencanto finiseculares. Lo que no advierte Monroy es que en las grandes capitales hispanoamericanas, con sus ideales de progreso y cientificismo positivista, ya se estaba poniendo en evidencia la crisis de la modernidad occidental, ese nuevo orden que estaba despojando a los individuos de cualquier posible seguridad o certeza. Así lo expresa José Mariano Leyva:

Para los decadentes, como para otros pensadores, la modernidad -aun con sus democracias- no era necesariamente un aliento de optimismo. Si hacemos caso a Fromm [en El miedo a la libertad], buena parte del resquemor se encontraba en la creación del individuo moderno. Uno que ya no cuenta con el cobijo de muchas de las instituciones «autoritarias» de antaño como la Iglesia y las monarquías que no se debían cuestionar. Con la obtención de esa novedosa libertad, de esa independencia, viene también un «aislamiento creciente y el sentimiento que surge de este hecho: la insignificancia del individuo y su impotencia». La sustracción de un antiguo todo que hacía sentir al individuo como parte de algo más grande. El escape de aquella forma de pensamiento producía lo mismo libertad que soledad (Leyva, 2013: 4I).

Con distintos matices, esto es lo que expresa simbólicamente el hombre inútil, tanto europeo como hispanoamericano, y llegó a ser tan poderosa su presencia que, así como en Rusia Dobrolyubov advirtió sobre el mal del oblomovismo, en Hispanoamérica José Ingenieros se ocupó de señalar un mal semejante en su ensayo titulado El hombre mediocre (1913). Resulta relevante este estudio como parte de los antecedentes de la figura del hombre inútil en Hispanoamérica, ya que Ingenieros describe al hombre mediocre como un personaje cada vez más común y cuyos rasgos distintivos son los siguientes:

Están fuera de su órbita el ingenio, la virtud y la dignidad, [...] Condenados a vegetar, no sospechan que existe el infinito más allá de sus horizontes.

El horror de lo desconocido los ata a mil prejuicios, tornándolos timoratos e indecisos: nada aguijonea su curiosidad; carecen de iniciativa y miran siempre al pasado, como si tuvieran los ojos en la nuca. [...].

No vibran a las tensiones más altas de la energía; son fríos, aunque ignoren la serenidad; apáticos sin ser previsores; acomodaticios siempre, nunca equilibrados. No saben estremecerse de escalofrío bajo una tierna caricia, ni abalanzarse de indignación ante 
una ofensa. [...] Carecen de línea; su personalidad se borra como un trazo de carbón bajo el esfumino, hasta desaparecer. [... ] Su cerebro y su corazón están entorpecidos por igual, como los polos de un imán gastado (2010:58).

Visto así, el hombre mediocre lo es en todos los aspectos de su vida, y si bien muchas similitudes guarda con el hombre inútil, la principal diferencia reside en que el mediocre está incapacitado para hacer las cosas, mientras que el inútil decide a voluntad, lúcida y críticamente, no hacer nada, pues se trata ante todo de un hombre inteligente, con una sensibilidad aguda, muchas veces encarnado en un personaje artista o ideólogo.

Un último rasgo por destacar en la figura, aunque no se trata de una condición inherente a ella, es su confrontación con mujeres fuertes, dominantes, perversas o en extremo puras y bondadosas. Esta confrontación tiene lugar sobre todo en la narrativa finisecular, donde los protagonistas masculinos se ven muchas veces dominados por una mujer fatal (femme fatale) o irremediablemente seducidos por la pureza de una mujer angelical. Al hablar de la narrativa modernista, José Ricardo Chaves Pacheco ${ }^{18}$ apunta que en el primer Romanticismo es posible identificar este tipo de personajes que serán retomados por los escritores de fin de siglo para adaptarlos a las vertientes simbolista y decadente (232). «Los personajes centrales masculinos de las novelas modernistas suelen ser artistas o seres de gran sensibilidad (aunque solo sea sensual, no necesariamente imaginativa), como los personajes de Nervo y Rebolledo» (Chaves Pacheco, 2005: 237), lo mismo que el protagonista de De sobremesa de José Asunción Silva.

En la prosa decadentista, el enfrentamiento estará dado sobre todo entre hombres inútiles y mujeres fatales, casi diabólicas, a través de las cuales tiene lugar la intervención de la locura o las psicopatías mencionadas líneas arriba. Según José Mariano Leyva,

en la fantasía de los decadentistas, los hombres solían vacilar más que las mujeres. Solían tener tendencias masoquistas, mientras que las mujeres, fuertes y resueltas, presentaban un lado más sádico. Lo que es más, esto no ocurría con uno o dos autores. Eran perfiles que aparecían una y otra vez dentro de toda la corriente. Paradigmas de un momento de éticas revueltas, por definirse hacia la modernidad, hacia el siglo $\mathrm{xx}$. Así, en esta debilidad de los hombres, en su masoquismo, en su queja por un

18 Véase "La mujer es más amarga que la muerte": Mujeres en la prosa modernista de México», 2005. 
mundo que no los entusiasmaba, era que los detractores encontraban aquella parte femenina (Leyva, 2013: 103).

La falta de virilidad criticada en otros personajes (como el pollo o el dandi), en el decadentismo se presenta como algo mucho más complejo, producto de la transformación de las sociedades en una época convulsa para el individuo, y que en esta confrontación con una mujer activa adquiere otro matiz del simbolismo del hombre inútil.

\section{Conclusiones}

A lo largo de este recorrido hemos visto algunos de los antecedentes de la figura del hombre inútil en Hispanoamérica. Por una parte, a través personajes estereotípicos, como el pollo, el catrín y el dandi; y por otra, a través de estudios críticos y ensayos que evidencian el mal de fin de siglo como una especie de pandemia que estaba atacando el orden social desde adentro, pero que más bien fue sintomático de su resquebrajamiento y del nuevo orden impuesto en la Modernidad. En este punto me interesa destacar cómo es posible tender un puente entre estos personajes asediados por el mal del fin de siglo y los protagonistas de la narrativa vanguardista, y cómo este vínculo se puede leer como una asimilación y una reformulación de un mismo desencanto inherente al hombre inútil.

Las crisis destacadas en las primeras páginas de este trabajo, presentes en La casa de cartón o en las novelas de Pablo Palacio y los cuentos de Felisberto Hernández, precisamente se encargan de colocar como protagonista a un hombre inútil en conflicto con el mundo vertiginoso y lleno de incertidumbres en el que se encuentra, pero no sin una o varias notas de humor e ironía. Se trata de hombres inútiles, cuya inacción y cuyas reflexiones han dejado de oscilar entre la melancólica desesperanza de un Bartleby y la desidia obsesiva y al mismo tiempo destructiva de un Garcín («El pájaro azul» de Rubén Darío), o el sentimiento en exceso apasionado de un José Fernández de Sotomayor y Andrade (protagonista de De sobremesa), para incorporarse al cauce de un devenir impreciso, a través de personajes empequeñecidos, incongruentes o ridículos.

En las primeras décadas del siglo xx, el mal de fin de siglo no es ya el desasosiego ante el vertiginoso progreso de la civilización, tampoco la incertidumbre con respecto a lo que la nueva centuria traerá consigo; sigue siendo un malestar, pero ahora producto de las crisis contemporáneas, de la evidencia del fracaso de los pro- 
cesos civilizatorios, del estallido de conflictos bélicos de dimensiones nunca vistas, en fin, de lo que parece ser el resquebrajamiento definitivo del orden social. Si el hombre inútil decimonónico guardaba un cierto temor frente al porvenir y por eso se erigía, las más de las veces, melancólico y serio ante su futuro, el vanguardista se ufana al saber que no hay porvenir posible y ante lo irremediable no encuentra más que apelar a la risa, por eso se mueve en el absurdo, se empequeñece, se ridiculiza, asume lo frágil de su identidad; porque él mismo es ya un ser reducido en el gran andamiaje de la vida moderna. Un ejemplo representativo de esto lo encontramos en Vida del ahorcado (1932) de Pablo Palacio, novela fragmentaria protagonizada por Andrés Farinango, un hombre inútil para quien todas las facetas de su vida (laboral, amorosa, social) están condenadas al fracaso e incluso su vida misma está destinada a terminar en la horca. Farinango está inserto en la lógica absurda de una sociedad que constriñe a los individuos hasta sofocarlos, y lo que hace el protagonista en esta condición es empequeñecerse, ridiculizarse, asumirse como un hombre limitado, pero también exhibir las carencias de este sistema por medio de la risa y lo absurdo, por medio de una conciencia tan clara que al revelar su condición, no puede menos que ponerla en evidencia de la forma más descarnada.

Farinango y los demás miembros de esta sociedad viven en un cubo, es decir, al interior de una cuadratura perfecta e inflexible que los uniforma a todos como si fueran objetos apilados en una estantería. Si bien es cierto que por momentos salen del cubo, la vida en el exterior les resulta, por lo menos al protagonista, excesiva, amenazante, inestable. Su conflicto reside en no ser capaces de contener la vida de afuera del cubo, pero tampoco poder amoldarse a la vida limitadísima de adentro. Sin embargo, a pesar de su condición, Farinango destaca por ser un hombre de una lucidez extraordinaria, tal y como vemos en su discurso al inicio de la novela:

He aquí un producto de las oscuras contradicciones capitalistas que está en la mitad de los mundos antiguo y nuevo, en esa suspensión del aliento, en ese vacío que hay entre lo estable y el desbarajuste de lo mismo. Tú también estás ahí, pero tienes un gran miedo de confesarlo porque uno de estos días deberás dar el salto y no sabes si vas a caer de este o del otro lado del remolino. Mas aquí mismo estás enseñando las orejas, amigo mío, tú, enemigo del burgués, que ignoras el lado en donde caerás después del salto. Pero ya me lo aclaras todo: Estoy viviendo la transición del mundo. Aquí, delante de mí, está la volcadura de campana, del otro lado de la justicia, y aquí mismo, dentro de mí, están todos los siglos congelados, envejecidos y grávidos. Yo tengo un amor en estos siglos; yo tengo un amor en esta volcadura (Palacio, 2006: 92). 
Como se expresa en esta cita, el personaje se sabe en una encrucijada histórica marcada por la total incertidumbre, y esta plenitud de conciencia solo lo llevará a un enfrentamiento contra el orden del mundo contemporáneo. A lo largo de la novela, la vida de Farinango se va articulando como una sucesión de esfuerzos inútiles: su relación con una joven llamada Ana no funciona, su mejor amigo Bernardo muere, su hijo le resulta un ser incomprensible y se sugiere que lo aniquila entre sus brazos, no encaja del todo en las reuniones sociales en que participa. Al final, la sociedad entera lo somete a juicio, no solo por el presunto asesinato del hijo, sino por lo que él es y representa: un inadaptado, un imbécil, un cobarde, un ahorcado, un hombrecillo. ${ }^{19}$ Como en los ejemplos citados al inicio de estas páginas, el personaje de Andrés Farinango también expresa esa imposibilidad de forjarse una identidad en un mundo en crisis, sólo que en este caso, esa imposibilidad se traducirá al final en el suicidio del protagonista y en la condena a repetir el círculo vicioso de esta vida hasta el infinito, pues así culmina la novela: «Ahora bien: esta historia pasa de aquí a su comienzo, en la primera mañana de mayo; sigue a través de estas mismas páginas, y cuando llega de nuevo aquí, de nuevo empieza allá... Tal era su iluminado alucinamiento» (Palacio, 2006: 125).

Cabe destacar que esta es solo una faceta del hombre inútil vanguardista, pues también habrá uno más festivo, juguetón, que no necesariamente culmina en la muerte; como en los textos ya citados de Macedonio Fernández y Felisberto Hernández. Lo importante es que aunque en la narrativa de vanguardia el hombre inútil exhiba estas últimas características no significa que no se manifestaran sutilmente desde antes. Por ejemplo, en algunos cuentos de Eduardo Wilde como «Vida moderna» (I888) o «Meditaciones inopinadas» (I88I), encontramos hombres inútiles juguetones, capaces de reírse de sí mismos y de lo que les rodea; en plena crisis finisecular, pero con una actitud más bien cínica hacia los conflictos que aquejan a los demás. En la obra de este autor encontramos algunos de los rasgos del pollo y del dandi, como la frivolidad, la tendencia a llevar una vida regida por la ley del mínimo esfuerzo y un cierto cinismo, pero también una vocación lúdica mucho más compatible con la vanguardia.

Como hemos visto, lo que el hombre inútil expresa a lo largo del siglo xix es el nacimiento y la consolidación de la Modernidad con sus respectivas crisis y retos, sus incertidumbres y reajustes en cuanto al papel del individuo en la sociedad. En

19 Estos y otros epítetos le son atribuidos a Andrés Farinango a lo largo de la escena de la audiencia en la que es juzgado (Vida del aborcado en las Obras completas de Pablo Palacio, p. II7-I24). 
la encrucijada del xix hacia el xx, la figura va compenetrándose cada vez más con las tensiones y exigencias de las grandes urbes (faceta representada por el dandi), con la vida vertiginosa que tiene para ofrecer la ciudad moderna y que, en ciertos momentos, le lleva a la locura o la muerte; y en ocasiones, aunque en muy menor grado, a la risa. El hombre inútil protagonista de la vanguardia expresa un estadio posterior en este mismo conflicto: el del triunfo del individualismo y la libertad, el de la crisis identitaria del hombre moderno, el del ser que se niega a asumir la responsabilidad que el nuevo orden le ha impuesto y a quien no le queda más que empequeñecerse o reducirse casi hasta desaparecer.

\section{Bibliografía}

Baudelaire, Charles

2014 El pintor de la vida moderna, Trad. Martín Schifino, México: Taurus. Belauzarán, Ignacio

I860 Cartas de don Caralampio Molinero del Cerro a Doña Bibiana del Cerro, su mujer, vecinos de las Batuecas más remotas e ignoradas, sobre la felicidad $y$ ventura de vivir en la Corte, México: Imprenta de Vicente Segura.

Beltrán Almería, Luis

2017 Genvs. Genealogía de la imaginación literaria. De la tradición a la Modernidad, Barcelona: Calambur.

Beltrán Almería, Luis

2015 Simbolismo y Modernidad, ed. Silvia Manzanilla, México: Sedeculta, Conaculta.

Beltrán Almería, Luis

2016 "El hombre inútil en la novela española", en: Leonardo Funes (coord.), Hispanismos del mundo, diálogos y debates en ( $y$ desde) el Sur, Barcelona: Miño y Dávila Editores, pp. 25-32.

Betancourt, Luis Victoriano,

I867 Artículos de costumbres y poesías, Guanabacoa: Imprenta "La revista de almacenes".

Chaves Pacheco, José Ricardo

2005 "«La mujer es más amarga que la muerte»: Mujeres en la prosa modernista de México", en: Belem Clark y Elisa Speckman Guerra (eds.), La república de las letras. Asomos a la cultura escrita del México decimonónico. 
Vol. I. Ambientes, asociaciones y grupos. Movimientos, temas y géneros literarios, México: UnAm, 2005, pp. 23I-244.

Darío, Rubén

I968 "El pájaro azul", en: Azul, Madridः Espasa-Calpe.

De Cuéllar, José Tomás

2005 Ensalada de pollos, México: Porrúa.

Del Casal, Julián

1889-I890 “Tristeza fin de siglo”, en: Remedios Mataix (ed.), Crónica semanal, Biblioteca Virtual Miguel de Cervantes, recuperado de http:// www.cervantesvirtual.com/obra-visor/tristeza-fin-de-siglo-I889-189o/ html/3b218332-7a45-IIeI-bifb-oor63ebf5e63_2.html\#I_2_ (fecha de consulta: 4/or/20I8)

Díaz Dufóo, Carlos

I986 Cuentos nerviosos. Padre mercader, Xalapa: Universidad Veracruzana.

Díaz y de Ovando, Clementina

2005 "El café: refugio de literatos, políticos y de muchos otros ocios", en: Belem Clark de Lara y Elisa Speckman Guerra (eds.), La república de las letras. Asomos a la cultura escrita del México decimonónico. Vol. I. Ambientes, asociaciones y grupos. Movimientos, temas y géneros literarios, México: unam, pp. 75-88.

Dobrolyubov, Nicolai

2018 "'What is Oblomovism?", recuperado de https://www.amherst.edu/ media/view/297815/original/Dobroliubov.pdf (fecha de consulta: I8/or/2018)

Fernández de Lizardi, José Joaquín

2015 Don Catrín de la Fachenda, México, Porrúa.

Gayol, Sandra

1993 "Ámbitos de sociabilidad en Buenos Aires: despachos de bebidas y cafés, I850-1900", en Anuario del IEHs, viII, Tandil, pp. 257-273.

Goncharov, Iván A

1985 Oblomov, trad. Enrique de Juan, introd. Natalia Ujánova, Madrid: Planeta.

Hawthorne, Nathaniel

1920 "Wakefield" en: Ernest Rhys (ed.), Twice Told Tales, Londres y Toronto:

Dent \& Son's, pp. 92-99.

Hernández, Felisberto

20II "Libro sin tapas", en Obras completas, Vol. I, México: Siglo xxi, pp. I6-5I. 
Ingenieros, José

2010 El hombre mediocre, México: Época.

Jung, Carl Gustav

2011 "El problema anímico del hombre moderno", en Civilización en transición. Obra Completa, Vol. Io, Madrid: Trotta. pp. 7I-9I.

Jung, Carl Gustav

I970 Arquetipo e inconsciente colectivo, trad. Miguel Murmis, Barcelona: Paidós.

Leyva, José Mariano

2013 Perversos y pesimistas. Los escritores decadentes mexicanos en el nacimiento de la modernidad, México: Tusquets.

Martínez Carrizales, Leonardo

1998 De la perfecta expresión. Preceptistas iberoamericanos siglo XIX, coord. Jorge A. Ruedas de la Serna, México: unam.

Melville, Herman

I999 Bartleby, el escribiente, trad. Jorge Luis Borges, Barcelona: Plaza \& Janés.

Monroy, Atenedoro

1902 Valor estético de las obras de la escuela decadentista, Puebla: Imprenta Artística Miradores número I.

Nervo, Amado

2000 El castillo de lo inconsciente, México: CONACUlta, 2000.

Nervo, Amado

I935 "El bachiller" en Obras completas de Amado Nervo, Vol. XiII, Madrid: Biblioteca Nueva, pp. 9-57.

Ortega, Alicia

2014 "Pablo Palacio: descrédito de la realidad, bolo suburbano y escritura", en: Alicia Ortega Caicedo y Raúl Serrano Sánchez (eds.) en Guaraguao. Revista de Cultura Latinoamericana. Jorge Icaza, Pablo Palacio y las vanguardias latinoamericanas, Núm. 33, Ecuador: Universidad Andina Simón Bolívar, pp. 133-I54.

Owen, Gilberto

I969 "La llama fría”, en* Francisco Monterde (selecc* y pról.), 18 novelas de El Universal Ilustrado, México: Bellas Artes, pp. 240-256.

Palacio, Pablo

2006 Obras completas, Quito: UNAP.

Peña Muñoz, Manuel

200I Los cafés literarios en Chile, Santiago: RIL Editores. 
Rebolledo, Efrén

I900 El enemigo, Ed. de la Revista Moderna, México: E. Dublan Impresor. Silva, José Asunción

2014 De sobremesa, México: conaculta, 2014. V.V. A.A.

1852 Los cubanos ilustrados por sí mismos. Galería de tipos cubanos, La Habana: Imprenta y papelería de Barcina, Tomo I.

Verani, Hugo J.

I998 "La heterogeneidad de la narrativa vanguardista hispanoamericana", en Revista de Crítica Literaria Latinoamericana, Año 24, No. 48, pp. II7-I27.

Verani, Hugo J.

1989 "La casa de cartón de Martín Adán y el relato vanguardista hispanoamericano", en AIr Actas, Centro Virtual Cervantes, pp. I077-1084.

Wilde, Eduardo,

1899 Prometeo E Cía, Buenos Aires: Imp., Litog., y Encuadernación de Jacobo Peuser.

Karla L. Marrufo Huchim

Doctora en Literatura Hispanoamericana por la Universidad Veracruzana. Actualmente realiza un posdoctorado en el Centro Peninsular en Humanidades y Ciencias Sociales (cephcis) de la Universidad Nacional Autónoma de México, con el proyecto de investigación "La figura del hombre inútil en la narrativa de vanguardia hispanoamericana". Estudió la maestría en Literatura Mexicana en la Universidad Veracruzana y la Licenciatura en Letras Hispánicas en la Universidad Modelo. Entre sus publicaciones recientes se pueden mencionar "Los rostros de la Diosa. Aproximación a la poética de Aurora Reyes", capítulo incluido en el volumen Chispas de luz rebelde. Mujeres y producción cultural en el México posrevolucionario, aprobado y en proceso de edición por la editorial de la Universidad Veracruzana;"Dos versiones de Orfeo y Eurídice", artículo incluido en el volumen Deslindes paranovelísticos, publicado por la Institución Fernando el Católico-Consejo Superior de Investigaciones Científicas de Zaragoza, España; "Visibilización de sistemas regionales: el Sureste", capítulo escrito en coautoría con Silvia A. Manzanilla Sosa y Judith Buenfil Morales, e incluido en Historia de las literaturas en México. Hacia un nuevo siglo (1968-2012), editado por la UNAM. 
Citar como: Karla L. Marrufo Huchim (2019), "El hombre inútil en la literatura de Hispanoamérica: antecedentes del siglo XIx a la vanguardia", Iztapalapa. Revista de Ciencias Sociales y Humanidades, núm. 86, año 40, enero-junio de 2019, ISSN: 2007-9176; pp. 67-92. Disponible en <http:// revistaiztapalapa.izt.uam.mx/index.php/izt/issue/archive $>$. 